\title{
Role of Dynorphin and GABA in the Inhibitory Regulation of NMDA- induced Dopamine Release in Striosome- and Matrix-enriched Areas of the Rat Striatum
}

\author{
Marie-Odile Krebs, Christian Gauchy, Marcel Desban, Jacques Glowinski, and Marie-Louise Kemel \\ Chaire de Neuropharmacologie, INSERM U114, Collège de France, 75231 Paris cedex 05, France
}

Using a new superfusion procedure in vitro, we have previously reported that the NMDA-evoked release of newly synthesized ${ }^{3} \mathrm{H}$-dopamine (DA) was higher in matrix- than in striosome-enriched areas of the rat striatum. In addition, GABAergic medium-sized spiny neurons were shown to be indirectly involved in this regulation. Since dynorphin and GABA are colocalized in a population of medium-sized spiny neurons, the role of dynorphin-containing neurons in the NMDA-evoked release of ${ }^{3} \mathrm{H}$-DA has been investigated using the same superfusion procedure on rat striatal slices. (1) The NMDA (50 $\mu \mathrm{M}, 25$ min application)-evoked release of ${ }^{3} \mathrm{H}$ DA was increased in the presence of naloxone (1 $\mu \mathrm{M}$, continuously delivered) in both striatal compartments, the overall response being more elevated in the striosome-enriched area. (2) The TTX (1 $\mu \mathrm{M}$, continuously delivered)-resistant NMDA-evoked responses were also enhanced in the presence of naloxone, but in this case, the disinhibitory effects of naloxone were similar in striosome- and matrix-enriched areas. (3) The selective $\kappa$-agonist U-50488 (1 $\mu \mathrm{M})$ totally reversed the naloxone-disinhibitory effect on the NMDA-evoked response in the matrix-enriched area, but only partially in the striosome-enriched area. It also completely prevented the disinhibitory effect of naloxone on the TTX-resistant NMDA-evoked release of ${ }^{3} \mathrm{H}-\mathrm{DA}$ in both compartments. (4) The bicuculline (5 $\mu \mathrm{M})$ - and naloxone (1 $\mu \mathrm{M})$-disinhibitory effects on the NMDA-evoked release of ${ }^{3} \mathrm{H}-\mathrm{DA}$ were additive in the matrix- but not in the striosome-enriched areas. Together, these results indicate that, under the action of NMDA, in addition to GABA, dynorphin is released from a population of medium-sized spiny neurons, and that this opiate peptide inhibits the NMDA-evoked release of DA in both striatal compartments through a TTX-resistant process. In addition, in the striosome-enriched area, NMDA activates another inhibitory local circuit that is TTX sensitive and could involve $\mu$-opiate receptors. Finally, the inhibitory effects mediated by GABA and opioid peptide(s) seem to be segregated in the matrix-but not in the striosome-enriched areas.

[Key words: excitatory amino acid, NMDA, GABA, dynorphin, presynaptic regulation, dopamine, striatal compartments]

\footnotetext{
Received June 11, 1993; revised Oct. 1, 1993; accepted Oct. 14, 1993.

This study was supported by INSERM, the Collège de France, and grants from Rhône-Poulenc Rorer, Human Frontiers, and Caisse Nationale de l'Assurance Maladie des Travailleurs Salariés.

Correspondence should be addressed to Marie-Louise Kemel, Chaire de Neuropharmacologie, INSERM U1 14, College de France 11, place Marcelin Berthelot, 75231 Paris cedex 05, France.

Copyright (C) 1994 Society for Neuroscience $0270-6474 / 94 / 142435-09 \$ 05.00 / 0$
}

All cortical areas project to the striatum and most if not all corticostriatal neurons are glutamatergic. These corticofugal glutamatergic neurons contact principally the medium-sized spiny efferent GABAergic neurons, forming asymmetric synapses on spines of their distal dendrites (Wilson and Groves, 1980; Somogy et al., 1981). According to electron microscopic studies, these spines are also contacted by the nigrostriatal dopaminergic (DA) neurons (Freund et al., 1984; Smith and Bolam, 1990). In addition, from combined lesion and histochemical investigations, there is also some indication for the existence of axoaxonic contacts or appositions between corticostriatal neurons and DA fibers (Bouyer et al., 1984). Reciprocal interactions have been shown between these striatal afferent neurons. Indced, DA was found to regulate both the transport and release of glutamate by acting on DA receptors of the $\mathrm{D}_{2}$ type (Nieoullon et al., 1983) and a presynaptic facilitatory influence of glutamate on DA release has been described (Giorguieff et al., 1977; Roberts and Sharif, 1978; Chéramy et al., 1986). Studies performed either in vivo (Barbeito et al., 1990; Leviel et al., 1990; Galli et al., 1991) or on striatal slices in the presence of TTX (Roberts and Anderson, 1979; Snell and Johnson, 1987; Clow and Jhamandas, 1989; Ranson and Deschenes, 1989; Krebs et al., 1991a) and on synaptosomes (Johnson and Jeng, 1991; Krebs et al., 1991a,b; Wang, 1991; Desce et al., 1992) have indicated that the glutamatergic receptors involved in the direct presynaptic regulation of DA release are of both the $\alpha$-amino-3-hydroxy-5methylisoxazole-4-propionic acid (AMPA) and NMDA type.

In addition, there is also evidence that glutamate regulates indirectly the release of DA through local circuits. This has been shown either in vivo using high concentrations of glutamate (Chéramy et al., 1986; Leviel et al., 1990) or in vitro by examining the effects of NMDA on the release of DA in striatal compartments (Krebs et al., 1991 b). Indeed, the striatum is an heterogeneous structure in which two main anatomical compartments can be distinguished: the striosomes (or patches) and the matrix (Graybicl and Ragsdalc, 1978). These compartments differ not only by several biochemical markers but also by the origin of their cortical glutamatergic and mesencephalic DA afferent projections or the target areas of their efferent connections (Graybiel, 1990; Gerfen, 1992). This has led us to use a new procedure allowing the superfusion on coronal or sagittal brain sections of striosome- and matrix-enriched areas $\left({ }^{3} \mathrm{H}\right.$-naloxone binding being the marker of the striosomes territories) of the rat striatum in order to look for differences in the presynaptic regulation of $\mathrm{DA}$ release in these compartments. Several observations were made by comparing the effects of NMDA on the release of ${ }^{3} \mathrm{H}$-DA continuously synthesized from ${ }^{3} \mathrm{H}$-tyrosine in these restricted and well-defined striatal areas. (1) In the 
absence of magnesium, the NMDA-evoked release of ${ }^{3} \mathrm{H}-\mathrm{DA}$ was found to be much more pronounced in matrix- than in striosome-enriched areas. (2) This difference was abolished in the presence of TTX and, in this condition, the TTX-resistant NMDA responses were similar in both striatal compartments. These results suggested, first, that NMDA receptors involved in the direct presynaptic regulation of DA release were located on DA nerve terminals in both compartments, and second, that an indirect facilitation of DA release mediated by a yet unidentified transmitter released under the action of NMDA occurred only in the matrix (Krebs et al., 1991b). (3) An indirect inhibitory regulation of DA release was also demonstrated due to the combined stimulatory effect of NMDA on the mediumsized GABAergic efferent neurons. Indeed, in the presence of bicuculline (a GABA receptor antagonist), the NMDA-evoked release of ${ }^{3} \mathrm{H}-\mathrm{DA}$ was markedly enhanced in both striatal compartments, and this disinhibitory effect was much more pronounced in the striosome-enriched area. (4) Finally, the TTXresistant NMDA responses were also found to be enhanced in the presence of bicuculline but, in this case, changes in ${ }^{3} \mathrm{H}-\mathrm{DA}$ release were similar in both compartments. Therefore, it was postulatcd that in the presence of TTX, NMDA stimulates the release of GABA from dendritic spines of medium-sized neurons and that, in turn, GABA inhibits the release of DA by acting on $\mathrm{GABA}_{\mathrm{A}}$ receptors located on DA nerve terminals (Krebs et al., 1993).

The present study was mainly undertaken to determine whether, under the action of NMDA, dynorphin, which is colocalized with GABA in a population of medium-sized spiny neurons (Gerfen and Young, 1988; Besson et al., 1990; Graybiel, 1990; Gerfen, 1992), can be involved, like GABA, in an inhibitory control of DA release in both striatal compartments of the rat striatum. This hypothesis was supported by studies performed on whole striatal slices (Mulder et al., 1984, 1989; Werling et al., 1988; Gauchy et al., 1991) or synaptosomes (Werling et al., 1988), which have indicated that either dynorphin or $\kappa$-opiate agonists inhibit the evoked release of DA. In addition, we have previously shown in the cat caudate nucleus that, besides a direct presynaptic facilitatory influence on DA release observed in both compartments, ACh also induces indirect inhibitory responses in the matrix, which involve either GABA or dynorphin, depending on the matrix area investigated (Kemel et al., 1992).

\section{Materials and Methods}

Experiments were performed using Sprague-Dawley male rats (200-250 gm; Charles River, France) kept for at least $8 \mathrm{~d}$ in a controlled environment of light (8 A.M., 8 P.M.), temperature, and humidity. They were killed by decapitation during the light period.

Determination of striosome- and matrix-enriched areas in the striatum. As previously described (Krebs et al., $199 \mathrm{lb}$; Desban et al., 1993), striosome- and matrix-enriched areas were shown on either coronal or sagittal brain sections following autoradiographic visualization of ${ }^{3} \mathrm{H}$ naloxone binding to $\mu$-opiate receptors, a specific striosome marker. The striosome compartment exhibits a complex labyrinthine organization; nevertheless, a prominent striosome territory observed in the rostral pole of the striatum, and a large laterocaudal matrix field were observed from one animal to another. Consequently, the striosome area was selected on rostral coronal slices (anteriority, 11.6>A $>10.6$ ) or on medial sagittal slices, near the anterior border $(1.8<\mathbf{L}<2.5$; according to the coordinates of Paxinos and Watson, 1986; in millimeters); in this precise area the striosome corresponds to about $70-80 \%$ of the tissue under investigation. Matrix-enriched areas were chosen on caudal coronal slices (behind 9.4) or on the most lateral sagittal brain sections, in which the matrix represents a large territory $(3.8<\mathrm{L}<$
4.8); in this area the percentage of matrix tissue analyzed is near $100 \%$. Since the definition of these zones, especially the matrix-enriched areas, was easier on sagittal sections, most experiments were performed on sagittal sections.

Superfusion experimental device. As previous described (Kemel et al., 1989; Krebs et al., 1989), brains were rapidly removed and placed in a cool magnesium-free artificial cerebral spinal fluid (CSF). Thick slices $(1-1.2 \mathrm{~mm})$ were cut using a vibratome, at the appropriate laterality or anteriority, and were placed into the superfusion chamber containing the magnesium-free medium, saturated with $\mathrm{O}_{2}: \mathrm{CO}_{2}(95: 5, \mathrm{v} / \mathrm{v})$, maintained at $34^{\circ} \mathrm{C}$, which was continuously renewed $(1.3 \mathrm{ml} / \mathrm{min})$ using a peristaltic pump. Microsuperfusion cannulas were placed vertically onto each selected area of the slices. The magnesium-free artificial CSF, containing $\mathrm{L}\left(3,5-{ }^{3} \mathrm{H}\right)$-tyrosine $(50 \mathrm{Ci} / \mathrm{mmol}, 60 \mu \mathrm{Ci} / \mathrm{ml}$; New England $\mathrm{Nu}$ clear) and the pharmacological compounds to be tested, was continuously delivered through each superfusion device using another peristaltic pump $(50 \mu 1 / \mathrm{min})$. This procedure allowed the estimation of the release of ${ }^{3} \mathrm{H}$-DA continuously synthesized from ${ }^{3} \mathrm{H}$-tyrosine. Superfusates were collected in successive $5 \mathrm{~min}$ fractions after $40 \mathrm{~min}$ when the spontaneous release of ${ }^{3} \mathrm{H}-\mathrm{DA}$ had reached a steady state.

Estimation of ${ }^{3} \mathrm{H}-\mathrm{DA} .{ }^{3} \mathrm{H}-\mathrm{DA}$ contained in a $200 \mu \mathrm{l}$ aliquot of each superfusate fraction was estimated after its separation from ${ }^{3} \mathrm{H}$-tyrosine and ${ }^{3} \mathrm{H}$-metabolites using successive ion-exchange chromatography and alumina adsorption as previously described (Nieoullon et al., 1978). The spontaneous release of ${ }^{3} \mathrm{H}$-DA was estimated during the first four superfusate fractions, and the evoked release of ${ }^{3} \mathrm{H}-\mathrm{DA}$ in each successive fraction was then expressed as a percentage of the average spontaneous release.

Pharmacological treatments. The artificial CSF had the following composition: $\mathrm{NaCl}, 126.5 \mathrm{mM} ; \mathrm{NaHCO}_{3}, 27.5 \mathrm{~mm} ; \mathrm{KCl}, 2.4 \mathrm{~mm}$ $\mathrm{KH}_{2} \mathrm{PO}_{4}, 0.5 \mathrm{~mm} ; \mathrm{CaCl}_{2}, 1.1 \mathrm{~mm} ; \mathrm{Na}_{2} \mathrm{SO}_{4}, 0.5 \mathrm{~mm}$; glucose, $5.9 \mathrm{~mm}$. When added, TTX $(1 \mu \mathrm{M})$, naloxone $(1 \mu \mathrm{M})$, or bicuculline $(5 \mu \mathrm{M})$ was present throughout the superfusion; NMDA $(50 \mu \mathrm{M})$ was applied for 25 $\mathrm{min}$ up to the end of the experiment, $65 \mathrm{~min}$ after the beginning of the superfusion. In some experiments, naloxone was applied alone for 25 $\mathrm{min}, 65 \mathrm{~min}$ after the beginning of the superfusion to determine its effect on the spontaneous release of ${ }^{3} \mathrm{H}-\mathrm{DA}$. All compounds were obtained from Sigma.

Statistical analysis. Differences between treatments were evaluated with the two-tailed Student's $t$ test $(n>7)$ or the nonparametric MannWhitney $U$ test (for preliminary effect; $n=3$ ). When multiple comparisons were made, results were analyzed using ANOVA; individual comparisons between treatments were evaluated with the Scheffe $t$ test. The level for significance was set at $p<0.05$.

\section{Results}

NMDA-induced release of ${ }^{3} \mathrm{H}-\mathrm{DA}$ in the presence of naloxone in striatal compartments

In all experiments, naloxone was used at a concentration of 1 $\mu \mathrm{M}$ in order to block not only $\mu$-opiate receptors but also those of the $\kappa$ and $\delta$ types. Preliminary experiments indicated that naloxone $(1 \mu \mathrm{M})$ increased slightly but uniformly the spontaneous release of ${ }^{3} \mathrm{H}$-DA in striosome- and matrix-enriched areas when it was applied alone $65 \mathrm{~min}$ after the beginning of the superfusion with ${ }^{3} \mathrm{H}$-tyrosine. However, in NMDA experiments, naloxone was continuously delivered from the onset of the superfusion. In this condition, as determined in the four 5 min fractions collected before the addition of NMDA, the spontaneous release of ${ }^{3} \mathrm{H}-\mathrm{DA}$ from naloxonc-trcatcd tissucs was stable and not significantly different from that observed in control experiments.

As previously shown (Krebs et al., $1991 \mathrm{~b}$ ), in the absence of magnesium, NMDA (50 $\mu \mathrm{M})$ stimulated the release of ${ }^{3} \mathrm{H}-\mathrm{DA}$ in both striatal compartments, these effects reaching a maximal amplitude during the first 5 min of the NMDA application. In addition, and of particular interest, the NMDA response was much higher in matrix- than in striosome-enriched areas (248 $\pm 12 \%$ and $161 \pm 6 \%$ of the spontaneous ${ }^{3} \mathrm{H}-\mathrm{DA}$ release values, respectively). 
When naloxone $(1 \mu \mathrm{M})$ was continuously added into the superfusion medium, NMDA-evoked responses were significantly higher than in the control condition $(298 \pm 12 \%$ and $221 \pm$ $12 \%$ of the spontaneous ${ }^{3} \mathrm{H}$-DA release values during the first 5 min of the NMDA application in matrix- and striosomeenriched areas, respectively) (Fig. 1). Moreover, this disinhibitory effect of naloxone was more pronounced in striosome- than in matrix-enriched areas. Indeed, as estimated from the average 25 min NMDA-evoked release of ${ }^{3} \mathrm{H}$-DA (mean evoked release of ${ }^{3} \mathrm{H}-\mathrm{DA}$ above spontaneous release expressed on a $5 \mathrm{~min}$ basis), in the presence of naloxone, the stimulatory effects of NMDA were about 2.2- and 1.4-fold those observed with NMDA alone in the striosome- and matrix-enriched areas, respectively (Fig. 1, Table 1). Nevertheless, in the presence of naloxone, the NMDA response was still significantly higher in matrix- than in striosome-enriched areas, since the ratios of the average NMDA responses in matrix- and striosome-enriched areas $\left(R_{M}\right.$ s) were, respectively, 1.4 and 2.2 in the presence and absence of the opiate antagonist (Table 1).

Similar results were obtained when coronal slices were used instead of sagittal slices. Indeed, in the presence of naloxone (1 $\left.\mu_{\mathrm{M}}\right)$, the NMDA-evoked release of ${ }^{3} \mathrm{H}$-DA was enhanced in striasome- and matrix-enriched areas (respectively selected in rostral and caudal slices) and the disinhibitory effect of naloxone was more prominent in the striosome-enriched area (data not shown).

\section{Effect of the $\kappa$-agonist $U-50488$ on the naloxone-induced disinhibition of the NMDA-evoked release of ${ }^{3} \mathrm{H}-\mathrm{DA}$}

The results obtained in the presence of naloxone suggest that in control conditions (absence of the opiate antagonist) NMDA stimulates the release of an endogeneous opiate peptide from striatal neurons and that this peptide, in turn, inhibits the release of ${ }^{3} \mathrm{H}-\mathrm{DA}$. Dynorphin, which is contained in a population of striatal efferent neurons, is known to inhibit presynaptically the release of DA by acting on $\kappa$-opiate receptors (Mulder et al., 1984; Werling et al., 1988; Gauchy et al., 1991). Therefore,

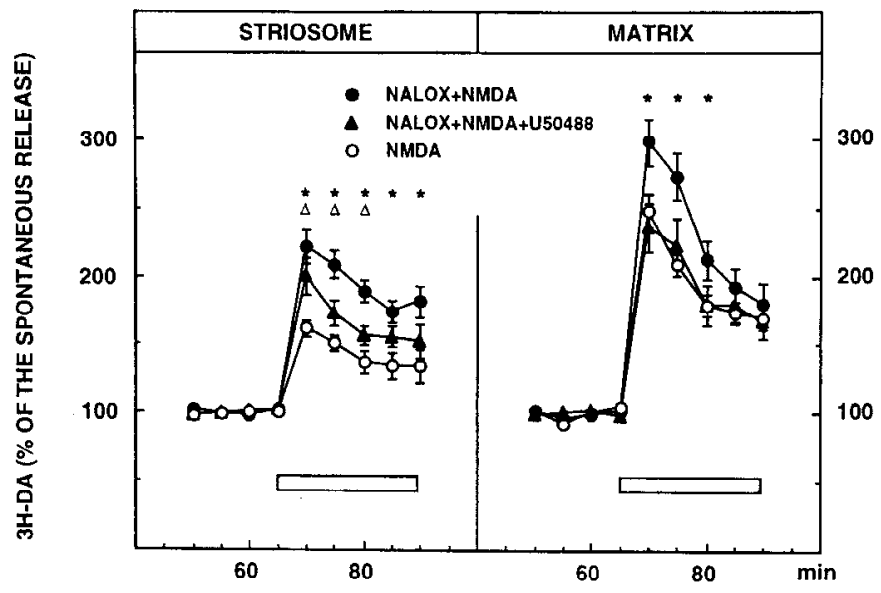

Figure 1. Disinhibition by naloxone of the NMDA-evoked release of ${ }^{3} \mathrm{H}$-DA in striosome- and matrix-enriched areas and reversal by the $\kappa$-opiate agonist U-50488. Experiments were performed on sagittal brain slices, microsuperfusion devices being applied vertically in either striosome- or matrix-enriched areas of the rat striatum as described in $\mathrm{Ma}$ terials and Methods. NMDA $(50 \mu \mathrm{M})$ and, when used, U-50488 $(1 \mu \mathrm{M})$ were added for $25 \mathrm{~min}, 65 \mathrm{~min}$ after the beginning of the superfusion with the ${ }^{3} \mathrm{H}$-tyrosine-containing, magnesium-free medium. When used, naloxone $(N A L O X ; 1 \mu \mathrm{M})$ was present throughout the superfusion. ${ }^{3} \mathrm{H}$ DA release, estimated in successive 5 min fractions, is expressed as a percentage of the spontaneous release determined in the first four fractions preceding NMDA application. Values are the means \pm SEM of data obtained in 9-17 experiments. ${ }^{*}, p<0.05$ for effect of NMDA in the presence of naloxone (NALOX+NMDA; striosome $n=17$, matrix $n=15$ ) when compared to that observed with NMDA alone (NMDA; striosome $n=11$, matrix $n=9$ ); $\Delta, p<0.05$ for combined effects of NMDA plus $U-50488$ in the presence of naloxone (NALOX+NMDA+U50488; striosome $n=9$, matrix $n=11$ ) when compared to that observed with NMDA alone $(N M D A)$.

complementary experiments were performed with U-50488 (trans-3,4-dichloro- $N$-methyl- $N$ [2-(1 pyrrolidinyl)cyclohexyl] benzeneacetamide), a selective agonist of these $\kappa$-opiate receptors, this drug being added for $25 \mathrm{~min}$ with NMDA.

\section{Table 1. Effects of naloxone and TTX on the NMDA-evoked release of ${ }^{3} \mathrm{H}-\mathrm{DA}$ in striatal} compartments

\begin{tabular}{|c|c|c|c|c|c|}
\hline & \multicolumn{2}{|c|}{$\begin{array}{l}{ }^{3} \mathrm{H}-\mathrm{DA}-\text {-evoked release in } \\
5 \mathrm{~min}(\%)\end{array}$} & \multirow[b]{2}{*}{$R_{M / S}$} & \multicolumn{2}{|c|}{$\begin{array}{l}\text { Multiplication } \\
\text { factor }\end{array}$} \\
\hline & $\mathrm{S}$ & $\mathbf{M}$ & & $\mathbf{S}$ & $\mathbf{M}$ \\
\hline NMDA & $+43 \pm 6$ & $+96 \pm 8$ & 2.2 & & \\
\hline NALOX + NMDA & $+94 \pm 6$ & $+131 \pm 10$ & 1.4 & 2.2 & 1.4 \\
\hline \multicolumn{6}{|l|}{ NALOX + NMDA } \\
\hline$+\mathrm{U}-50488$ & $+67 \pm 7$ & $+97 \pm 11$ & 1.4 & 1.6 & 1.0 \\
\hline \multicolumn{6}{|l|}{ NALOX + BICU } \\
\hline + NMDA & $+227 \pm 27$ & $+290 \pm 32$ & 1.3 & 5.3 & 3.0 \\
\hline TTX + NMDA & $+53 \pm 6$ & $152 \pm 6$ & 1.0 & & \\
\hline \multicolumn{6}{|l|}{ TTX + NALOX } \\
\hline + NMDA & $+101 \pm 9$ & $+96 \pm 9$ & 0.9 & 1.9 & 1.8 \\
\hline \multicolumn{6}{|l|}{ TTX + NALOX } \\
\hline + NMDA + U-50488 & $+63 \pm 9$ & $+50 \pm 7$ & 0.8 & 1.2 & 1.0 \\
\hline
\end{tabular}

Experiments are those described in Figure 2 and following. Calculations were made from data (expressed as percentage) reported in these figures. In all cases, whatever the treatment, naloxone (NALOX), tetrodotoxin (TTX), naloxone + TTX, or naloxonc + bicuculline (BICU), the mean value of ${ }^{3} \mathrm{H}-\mathrm{DA}$ release during the overall $25 \mathrm{~min}$ NMDA (50 $\left.\mu \mathrm{M}\right)-\mathrm{evoked}$ response (expressed on a $5 \mathrm{~min}$ basis) was determined minus the corresponding spontaneous release estimated at the same time in slices not exposed to NMDA. S, striosome-enriched areas; $M$, matrix-enriched areas. $R_{M / s}$, ratio of the mean values of NMDA-evoked responses in matrix- and striosome-enriched areas. Multiplication factor, ratio of the mean values of NMDA-evoked responses (with or without TTX) in the presence or absence of NALOX. 


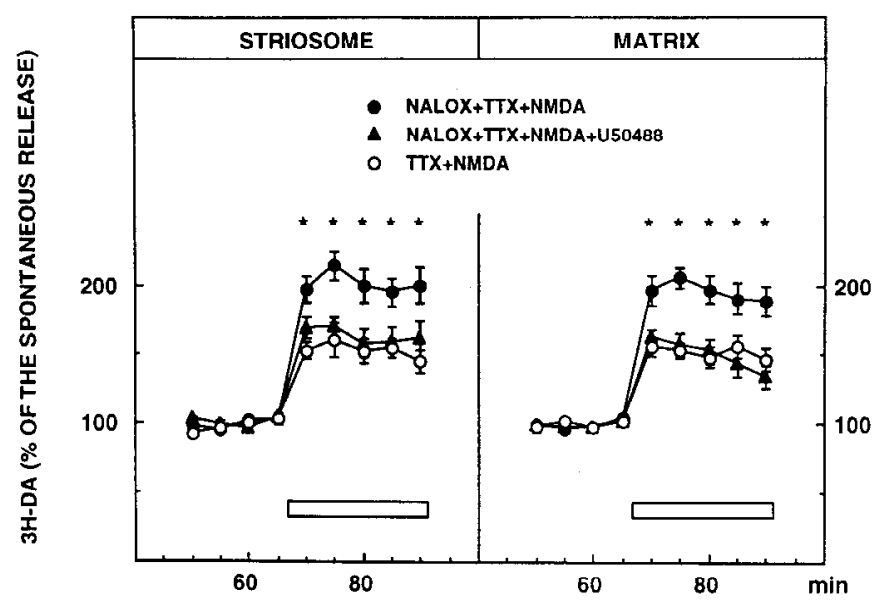

Figure 2. Disinhibition by naloxone of the TTX-resistant NMDAevoked release of ${ }^{3} \mathrm{H}-\mathrm{DA}$, reversal by the $\kappa$-opiate agonist U-50488. Experiments and expression of data are as described for Figure 1. NMDA $(50 \mu \mathrm{M})$ and $\mathrm{U}-50488(1 \mu \mathrm{M})$, when used, were added for $25 \mathrm{~min}, 65$ min after the beginning of the superfusion. TTX $(1 \mu \mathrm{M})$ and, when used, naloxone $(N A L O X ; 1 \mu \mathrm{M})$ were added throughout the superfusion. Results are the means \pm SEM of data obtained in 7-12 experiments. In all cases, values of TTX-resistant NMDA-evoked responses in either the presence or absence of naloxone $(1 \mu \mathrm{M})$ were significantly different from their respective controls. ${ }^{*}, p<0.05$ for effect of NMDA in the presence of naloxone and TTX (NALOX+TTX+NMDA; striosome $n$ $=13$, matrix $n=11$ ) when compared to the effect of NMDA in the presence of TTX alone (TTX+NMDA; striosome $n=9$, matrix $n=12$; previously published Krebs et al., 1991b).

In the matrix-enriched area, U-50488 $(1 \mu \mathrm{M})$ totally abolished the naloxone $(1 \mu \mathrm{M})$-induced disinhibition of the NMDA-evoked release of ${ }^{3} \mathrm{H}$-DA (Fig. 1). A partial effect only was observed in the striosome-enriched area, since U-50488 was without significant action during the first $5 \mathrm{~min}$ of the NMDA application, and the overall $25 \mathrm{~min}$ NMDA-evoked response was reduced by approximately $50 \%$ (Fig. 1 ).

Naloxone-induced disinhibition of the TTX-resistant NMDAevoked release of ${ }^{3} \mathrm{H}-\mathrm{DA}$ and reversal of this response by $U-50488$

TTX, a neurotoxin that blocks sodium channels, is generally used to prevent most indirect presynaptic regulation of DA release mediated by local circuits. As illustrated in Figure 2, the NMDA-evoked release of ${ }^{3} \mathrm{H}-\mathrm{DA}$ is partly resistant to the action of TTX, and similar responses occur in both striatal compartments in the presence of the neurotoxin $(1 \mu \mathrm{M})(153 \pm 6 \%$ and $156 \pm 7 \%$ of the spontaneous release values during the first 5 min of NMDA application in striosome- and matrix-enriched areas, respectively).

Surprisingly, naloxone still induced a disinhibitory effect on the NMDA-evoked release of ${ }^{3} \mathrm{H}$-DA in the presence of TTX, and NMDA responses were also of similar amplitude in both striatal compartments $(197 \pm 9 \%$ and $196 \pm 11 \%$ of the spontaneous ${ }^{3} \mathrm{H}-\mathrm{DA}$ release values during the first $5 \mathrm{~min}$ of NMDA application in striosome- and matrix-enriched areas, respectively) (Fig. 2, Table 1).

Interestingly, when U-50488 (1 $\mu \mathrm{M})$ was coapplied with NMDA, it totally counteracted the disinhibitory effect of naloxone on the TTX-resistant NMDA-cvoked relcase of ${ }^{3} \mathrm{H}-\mathrm{DA}$ in both compartments (Fig. 2). In addition, when U-50488 (1 $\mu \mathrm{M}$ ) was applied simultaneously with NMDA in the presence of TTX but in the absence of naloxone, the effect of NMDA pro-

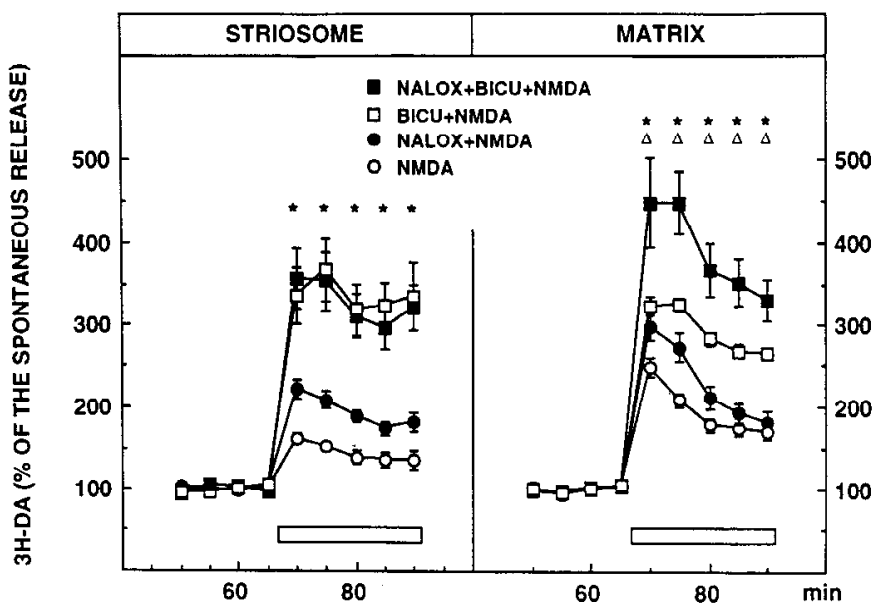

Figure 3. Disinhibition by the coapplication of naloxone and bicuculline of the NMDA-evoked release of ${ }^{3} \mathrm{H}$-DA in striosome- and matrix-enriched areas. Experiments and expression of data are as described for Figure 1 . When used, naloxone $(N A L O X ; 1 \mu \mathrm{M})$ and bicuculline $(B I C U ; 5 \mu \mathrm{M})$ were added throughout the superfusion. NMDA $(50 \mu \mathrm{M})$ was added for $25 \mathrm{~min}, 65 \mathrm{~min}$ after the beginning of the superfusion. Results are the means \pm SEM of data obtained in 8-17 cxpcriments. $*, p<0.05$ for effect of NMDA in the presence of both naloxone and bicuculline ( $N A L O X+B I C U+N M D A$; striosome $n=8$, matrix $n=8)$ when compared to the effect of NMDA in the presence of naloxone alone (NALOX+NMDA; striosome $n=17$, matrix $n=15)$ in the same area; $\triangle, p<0.05$ for effect of NMDA in the presence of both naloxone and bicuculline $(N A L O X+B I C U+N M D A)$ when compared to the effect of NMDA in the presence of bicuculline alone $(B I C U+N M D A$; striosome $n=17$, matrix $n=17$ ) in the same area.

gressively decreased (50\% after $15 \mathrm{~min}$ of NMDA + U-50488 application; data not shown).

Combined effects of bicuculline and naloxone on the NMDAevoked release of ${ }^{3} \mathrm{H}-\mathrm{DA}$

As previously shown (Krebs et al., 1993), the NMDA-evoked release of ${ }^{3} \mathrm{H}-\mathrm{DA}$ is markedly enhanced in the presence of the $\mathrm{GABA}_{\mathrm{A}}$ antagonist bicuculline $(5 \mu \mathrm{M})$, and this effect is much more pronounced in striosome- than in matrix-enriched areas. These data, qualitatively similar to those obtained with naloxone, suggest that, under the action of NMDA, both GABA and dynorphin, which are colocalized in a population of medium-sized spiny neurons (about $50 \%$ of the totality of these neurons; Gerfen and Young, 1988; Besson et al., 1990), can be released locally and, in turn, inhibit presynaptically the release of DA. Therefore, additional experiments were performed with bicuculline and naloxone to determine whether the inhibitory influences of GABA and dynorphin on DA release were additive or not.

As illustrated in Figures 3 and 4 and Table 1, large NMDAevoked responses were seen under the combined presence of bicuculline $(5 \mu \mathrm{M})$ and naloxone $(1 \mu \mathrm{M})$. The NMDA-evoked release of ${ }^{3} \mathrm{H}$-DA during the initial 10 min of the NMDA application was slightly but not significantly higher in matrix- than in striosome-enriched areas.

More precisely, in the matrix-enriched area, the NMDAevoked release of ${ }^{3} \mathrm{H}$-DA observed under bicuculline and naloxone was much higher than that found with each antagonist alone. Indeed, the response seen in the first $5 \mathrm{~min}$ of NMD $\Lambda$ application under both antagonists represented $449 \pm 53 \%$ of the spontaneous release value, while these responses were respectively of $323 \pm 26 \%$ and $298 \pm 12 \%$ under bicuculline or 


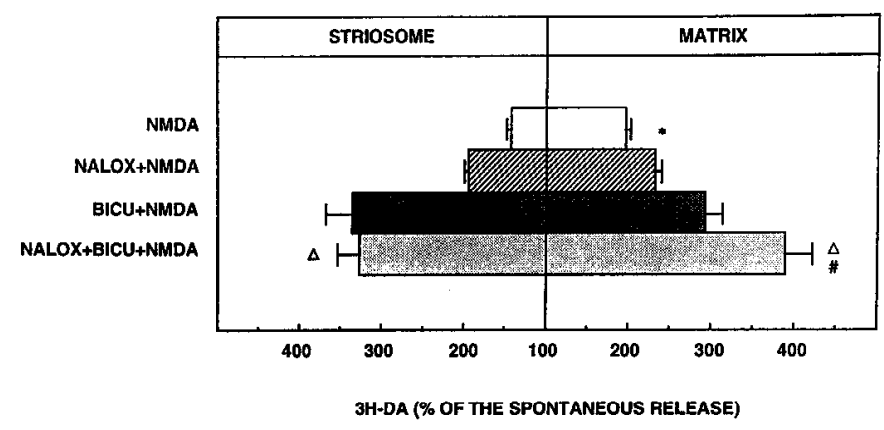

Figure 4. Additivity of the disinhibitory effects of naloxone and bicuculline on the NMDA-evoked release of ${ }^{3} \mathrm{H}$-DA in matrix- but not in striosome-enriched areas. Experiments and expression of data were performed as described in Figures 1 and 3. The mean evoked release of ${ }^{3} \mathrm{H}$-DA during the $25 \mathrm{~min}$ NMDA application (above the spontaneous release), was calculated and expressed on a $5 \mathrm{~min}$ basis. Results are the means \pm SEM of data obtained in 8-17 experiments. The effects of NMDA in the presence of bicuculline (BICU) and/or naloxone (NALOX) were significantly greater than the response obtained with NMDA alone $(N M D A)$ in the same compartment. ${ }^{*}, p<0.05$ for effect of NMDA in matrix area $(n=9)$ when compared to that obtained in striosomeenriched area $(n=11) ; \Delta, p<0.05$ for effect of NMDA in the presence of naloxone and bicuculline (NALOX+BICU+NMDA; striosome $n=$ 8 , matrix $n=8$ ) when compared to the NMDA-evoked response in the presence of naloxone $(N A L O X+N M D A$; striosome $n=17$, matrix $n=$ 15 ) in the same compartment; \#, $p<0.05$ for effect of NMDA in the presence of naloxone and bicuculline $(N A L O X+B I C U+N M D A$; striosome $n=8$, matrix $n=8$ ) when compared to the NMDA-evoked response in the presence of bicuculline $(B I C U+N M D A$; striosome $n=$ 17 , matrix $n=17$ ) in the matrix compartment.

naloxone alone. In the striosome-enriched area, NMDA responses observed with both bicuculline and naloxone or bicuculline alone were identical and significantly higher than that found with naloxone alone (responses in the first $5 \mathrm{~min}$ of the NMDA application represented, respectively, $356 \pm 37 \%, 335$ $\pm 35 \%$, and $221 \pm 12 \%$ of the spontaneous release values under both bicuculline and naloxone or bicuculline and naloxone alone) (Fig. 3).

As determined from the average 25 min NMDA responses (expressed on a $5 \mathrm{~min}$ basis), the disinhibitory effects of bicuculline and naloxone on the NMDA-evoked release of ${ }^{3} \mathrm{H}-\mathrm{DA}$ were additive in matrix- but not in striosome-enriched areas (Fig. 4).

\section{Discussion}

The validity of the microsuperfusion procedure used for investigating local circuits involved in the presynaptic regulation of DA release in striatal compartments has been extensively discussed in previous studies (Kemel et al., 1989, 1992; Gauchy et al., 1991; Krebs et al., 1991b, 1993; Tremblay et al., 1992). Using autoradiographic data obtained with ${ }^{3} \mathrm{H}$-naloxone, a ligand of $\mu$-opiate receptors selectively located in striosomes (Herkenham and Pert, 1981), and the three-dimensional reconstruction of the striosome compartment (Desban et al., 1993), highly enriched striosome areas and areas almost exclusively represented by the matrix could be selected in the rat striatum using either sagittal or coronal brain slices. The present results, mainly obtained with sagittal sections, provide additional information on the processes by which NMDA controls the release of $\mathrm{DA}$ in striatal compartments. Indeed, experiments performed in the presence of naloxone suggest that, under NMDA application, dynorphin is released from medium-sized spiny neurons and

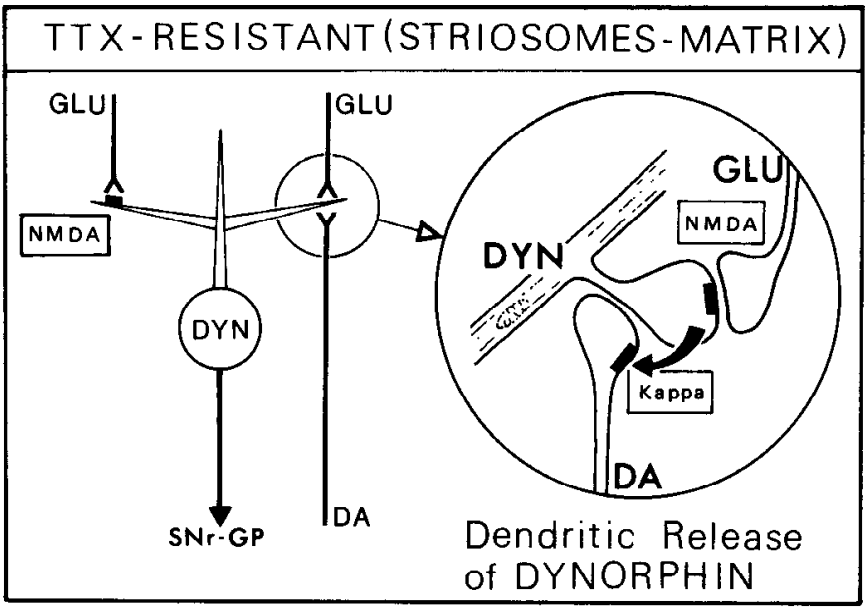

Figure 5. Schematic representation of the direct NMDA-evoked inhibitory control by dynorphin of DA release in striatal compartments. The disinhibitory effect of naloxone on the NMDA-evoked release of ${ }^{3} \mathrm{H}-\mathrm{DA}$, in the presence of TTX, can be observed in both striosomeand matrix-enriched areas: NMDA stimulates the release of dynorphin $(D Y N)$ from dendritic spines of the medium-sized spiny neurons, and dynorphin, in turn, through its action on presynaptic $\kappa$-receptors located on DA nerve terminals, reduces the NMDA-evoked release of ${ }^{3} \mathrm{H}$-DA. (The direct stimulatory effect of NMDA on the release of DA mediated by NMDA receptors located on DA nerve terminals that occurs in both compartments, and the involvement of opiates in the indirect NMDAevoked release of DA in striosomes are not represented in this schematic representation.) $G L U$, glutamate; $S N r-G P$, substantia nigra pars reticulata-globus pallidus.

that, in turn, it reduces the NMDA-evoked release of ${ }^{3} \mathrm{H}-\mathrm{DA}$. Differences were seen between the two striatal compartments since the disinhibitory effect of naloxone was more important in striosome- than in matrix-enriched areas. In addition, disinhibitory responses induced by bicuculline and naloxone were additive in matrix-but not in striosome-enriched areas. Finally, naloxone disinhibitory responses were also seen in the presence of TTX, suggesting the existence of functional interactions between glutamatergic and DA fibers through the dendrites of dynorphin-containing neurons (Fig. 5).

\section{Similar inhibitory control by dynorphin of the TTX-resistant NMDA-evoked release of ${ }^{3} \mathrm{H}-\mathrm{DA}$ in both striatal compartments}

TTX is generally used to prevent indirect presynaptic regulation of transmitter release involving neuronal activity. In this condition, some of the complex neuronal interactions are eliminated, thus facilitating the identification of local circuits contributing to the control of transmitter release.

As already indicated, in the absence of magnesium and presence of TTX, NMDA stimulates the release of ${ }^{3} \mathrm{H}-\mathrm{DA}$, and similar responses occur in both striatal compartments (Krebs et al., 1991b). This has led us to conclude that these TTXresistant NMDA-evoked responses were mediated by NMDA receptors located on DA nerve terminals (Krebs et al., 1991a). However, this interpretation can be challenged since nitric oxide, which is formed in some striatal cells possessing NMDA receptors, and nitric oxide synthase (somatostatin interneurons particularly) (Williams et al., 1991; Marin et al., 1993) have been shown to stimulate the release of D $\Lambda$ (Hansbauer et al., 1992; Zhu and Luo, 1992). Similarly, arachidonic acid formed in striatal neurons under the action of NMDA could play a critical role in the TTX-resistant NMDA-evoked release of DA 
(Dumuis et al., 1988). Nevertheless, results obtained on striatal synaptosomes have confirmed the existence of NMDA receptors on DA nerve terminals involved in a presynaptic facilitation of DA release (Johnson and Jeng, 1991; Krebs et al., 1991a; Wang, 1991; Desce et al., 1992). More recently, we have also reported that in the presence of TTX, bicuculline disinhibits the NMDAevoked release of ${ }^{3} \mathrm{H}-\mathrm{DA}$, and that this enhanced response is similar in both striatal compartments. Therefore, it was assumed that NMDA stimulates the release of GABA from dendrites of the medium-sized spiny GABAergic efferent neurons and that, in turn, GABA reduces the TTX-resistant NMDA-evoked release of ${ }^{3} \mathrm{H}$-DA by acting on $\mathrm{GABA}_{\mathrm{A}}$ receptors located on DA ncrve tcrminals (Krcbs ct al., 1993). This hypothesis was supported by other experiments. First, in the absence of magnesium, NMDA stimulated through a TTX-resistant process the release of preloaded ${ }^{3} \mathrm{H}$-GABA from striatal GABAergic neurons in both compartments, and second, the presence of NMDA receptors involved in a direct presynaptic facilitation of GABA release could not be observed on purified striatal synaptosomes (Galli et al., 1992). Finally, as demonstrated by other authors, the presence of both glutamatergic and DA synapses on dendritic spines of GABAergic cells provided the required anatomical basis for this hypothesis (Freund et al., 1984; Smith and Bolam, 1990).

We now show that the TTX-resistant NMDA-evoked release of ${ }^{3} \mathrm{H}-\mathrm{DA}$ is also enhanced under the continuous delivery of naloxone and that identical responses also occur in both striatal compartments. Therefore, this disinhibitory effect of naloxone on NMDA responses is comparable in several ways to that observed with bicuculline. By analogy, an opiate peptide acting on naloxone-sensitive receptors could be released from dendrites through a TTX-resistant process, this local release being dependent on the NMDA-mediated influx of calcium in dendrites of striatal neurons. Such an NMDA-mediated calcium influx has been demonstrated in cultured striatal neurons using the Indo-1 method (Murphy et al., 1987).

Several facts suggest that the released inhibitory opiate peptide is dynorphin. According to binding studies, $\kappa$-opiate receptors have a diffuse distribution in the striatum and are thus present in both striatal compartments (Tempel and Zukin, 1987; Sharif and Hughes, 1989). In addition, studies carried out on striatal slices have shown that either dynorphin or $\kappa$-opiate agonists inhibit the evoked release of DA (Mulder et al., 1984; Werling et al., 1988; Gauchy et al., 1991). This presynaptic inhibition of DA release was TTX-resistant and could even be demonstrated on striatal synaptosomes (Werling et al., 1988). Supporting our hypothesis, in our conditions, $\kappa$-opiate receptors are blocked by naloxone, and by competing with naloxone, the $\kappa$-opiate agonist U-50488 completely reversed the naloxonedisinhibitory effect on the TTX-resistant NMDA-evoked release of ${ }^{3} \mathrm{H}$-DA in both striatal compartments. Similarly, we have previously shown that dynorphin or U-50488 prevents the TTX-resistant ACh-evoked release of ${ }^{3} \mathrm{H}-\mathrm{DA}$ in striosome- and matrix-enriched areas of the cat caudate nucleus (Gauchy et al., 1991): Therefore, as in the cat, $\kappa$-opiate receptors involved in a presynaptic inhibition of DA release seem to be present on DA nerve terminals in striosome- and matrix-enriched areas of the rat striatum. In fact, dynorphin is colocalized with GABA in a population of medium-sized spiny neurons in both striatal compartments, those of the matrix innervate the substantia nigra pars reticulata and the internal globus pallidus, while those of striosomes predominantly project to the substantia nigra pars compact (Gerfen and Young, 1988; Graybiel, 1990; Gerfen, 1992).

At the concentration used $(1 \mu \mathrm{M})$, naloxone blocks not only $\kappa$ - but also $\mu$ - and $\delta$-opiate receptors. Therefore, besides dynorphin, other opiate peptides (met-enkephalin, particularly) could also be involved in the inhibitory control of the TTXresistant NMDA-evoked release of ${ }^{3} \mathrm{H}-\mathrm{DA}$. Although this cannot be completely excluded, this seems unlikely since results obtained on whole striatal slices have indicated that agonists of $\delta$-opiate receptors do not inhibit but stimulate the release of ${ }^{3} \mathrm{H}$ DA through a TTX-resistant process (Lubetzki et al., 1982; Petit et al., 1986). In addition, in contrast to $\delta$-opiate receptors, which have a diffuse distribution in the rat striatum (Tempel and $\mathrm{Zu}$ kin, 1987; Sharif and Hughes, 1989), $\mu$-opiate receptors are only present in striosomes (Herkenham and Pert, 1981). Finally, inhibitory modulations of DA release have been seen in vivo with $\mu$-opiate agonists (Chesselet et al., 1983; Pentney and Gratton, 1991) but these effects seem to be indirect since $\mu$-opiate agonists alone are without effect on the in vitro spontaneouse release of ${ }^{3}$ H-DA (Lubetzki et al., 1982).

\section{Distinct naloxone-sensitive inhibitory regulation of the $N M D A$-evoked release of ${ }^{3} H-D A$ in striatal compartments}

In contrast to the results obtained in the presence of TTX, marked differences are seen in the presynaptic regulation of DA release in striatal compartments of the rat in the absence of the neurotoxin. First, the NMDA-evoked release of ${ }^{3} \mathrm{H}-\mathrm{DA}$ is much more important in matrix- than in striosome-enriched areas (Krebs et al., 1991b). This seems to be due to a TTX-sensitive facilitatory process occurring selectively in the matrix that has still to be identified. Second, the disinhibitory effect of bicuculline on NMDA responses is much more pronounced in striosome-than in matrix-enriched areas, and this difference results mainly from the blockade of a TTX-sensitive inhibitory process occurring only in the striosome-enriched area (Krebs et al., 1993). Indeed, in this striatal compartment, GABA released through nerve activity from collateral fibers of medium-sized spiny neurons may also intervene in the inhihitory presynaptic regulation of DA release.

Differences were also observed between the two striatal compartments in the presence of naloxone and the absence of TTX. (1) The NMDA response was still higher in matrix- than in striosome-enriched areas. (2) The disinhibitory effect of naloxone was more pronounced in striosome- than in matrix-enriched areas. (3) The coapplication of the $\kappa$-opiate agonist U-50488 with NMDA completely reversed the disinhibitory effect of naloxone in matrix- (like in the presence of TTX) but not in striosome-enriched areas. This partial inhibitory effect of U-50488 on the NMDA response in the striosome-enriched area does not seem to be related to a too low concentration of this drug since, at this concentration, U-50488 completely reversed the naloxone-induced disinhibitory responses in the matrix in the absence of TTX as well as in both striatal compartments in the presence of TTX. Therefore, under the action of NMDA, besides dynorphin, another locally released inhibitory opiate peptide acting through naloxone-sensitive receptors could be responsible for this TTX-sensitive indirect inhibitory regulation of the NMDA response exclusively seen in striosomes. An opioid peptide acting only on $\mu$-opiate receptors could be involved in this effect. Indeed, $\mu$-opiate receptors are only present in striosomes and are mainly located on striatal spiny neurons (Herkenham and Pert, 1981; Hamel and Beaudet, 1984, 
1987). In addition, as shown in vivo, $\mu$-opiate agonists induce a delayed inhibition of DA release in the cat caudate nucleus (Chesselet et al., 1983) and, occasionally, a decreased evoked release of DA in the rat striatum (Pentney and Gratton, 1991). Experiments performed with $\mu$-opiate agonists are in progress to verify this hypothesis. Whatever the precise mechanism involved, these results indicate that the naloxone-sensitive inhibitory processes triggered by NMDA and intervening in the control of the evoked release of ${ }^{3} \mathrm{H}-\mathrm{DA}$ are more complex in striosome- than in matrix-enriched areas.

\section{Evidence for a segregated $G A B A$ and dynorphin inhibitory control of the NMDA-evoked release of ${ }^{3} H-D A$ in matrix-but not in striosome-enriched areas}

Previously, we have shown that $\mathrm{ACh}$ regulates in different ways the release of DA in compartments of the cat caudate nucleus. Indeed, in addition to a direct muscarinic facilitation of DA release seen in both compartments, $\mathrm{ACh}$ also exerts indirect inhibitory effects in the matrix by acting on medium-sized spiny neurons. Moreover, depending on the matrix areas investigated, the $\mathrm{ACh}$-evoked inhibitory regulation of DA release involves either GABA or dynorphin. Interestingly, the ACh-mediated GABAergic inhibitory regulation was observed in matrix sites containing groups of cells projecting to the substantia nigra pars reticulata (Kemel et al., 1992) while the ACh-mediated dynorphin inhibitory regulation occurred in an area in which diffusely distributed cells projecting to the internal globus pallidus and/ or the substantia nigra pars reticulata were present (M.-O. Krebs, C. Gauchy, M. Desban, J. Glowinski, and M.-L. Kemel, unpublished observations). This functional heterogeneity, linked to the anatomical heterogeneity of the matrix in the cat, led us to determine whether the disinhibitory effects of bicuculline and naloxone on the NMDA-evoked release of ${ }^{3} \mathrm{H}-\mathrm{DA}$ in striatal compartments of the rat were additive.

The bicuculline disinhibitory effect on the NMDA-evoked response is much more pronounced than that observed with naloxone in both striatal compartments. This is not surprising since all medium-sized spiny efferent neurons are GABAergic while only $50 \%$ of them also contain dynorphin (Gerfen and Young, 1988; Besson et al., 1990; Graybiel, 1990; Gerfen, 1992). Therefore, under the action of NMDA, GABA may be released to a larger extent than dynorphin. Moreover, the potency of the inhibitory effect of GABA on the NMDA-evoked release of ${ }^{3} \mathrm{H}$ DA could be more pronounced than that of dynorphin. In addition, as already discussed, the disinhibitory effects of either bicuculline or naloxone alone are more important in the striosome-enriched area since both TTX-sensitive and TTX-resistant inhibitory processes can be seen in this striatal compartment. In addition, as previously discussed, the TTX-sensitive naloxone disinhibitory process could implicate $\mu$-opiate receptors located on GABAergic medium-sized spiny neurons and conscquently an effect resulting from release of GABA. This could explain why the NMDA-evoked release of ${ }^{3} \mathrm{H}-\mathrm{DA}$ was not higher under the combined presence of naloxone and bicuculline than with bicuculline alone. In contrast, additive effects were observed in the matrix since the NMDA response seen under both bicuculline and naloxone was higher than that induced by bicuculline alone. This shows once more that local circuits participating in the presynaptic control of DA release differ in the two striatal compartments. In addition, the additivity of the disinhibitory effects of bicuculline and naloxone in the matrix suggests that under the action of NMDA, GABA and dynorphin may be released at different sites in this compartment. This could be related to the existence of an anatomical heterogeneity of the matrix in the rat as previously demonstrated in the cat (Kemel et al., 1992).

\section{Concluding remarks}

By acting through different types of DA receptors coupled to distinct transducing systems and located on striatal afferent fibers or intrinsic and efferent neurons, DA influences in several ways messages passing through the striatum. Appropriate regulatory processes triggered by incoming signals must continuously control DA transmission for adaptive responses of striatal efferent cells. Changes in the firing rate of DA cells and presynaptic processes, which may or may not depend on striatal local circuits, play a critical role in such regulation. The corticostriatal glutamatergic neurons that innervate the striosomes originate from deep cortical layers, while those projecting to the matrix are located more superficially (Gerfen, 1989). The respective roles and relationships of these distinct cortical inputs have still to be elucidated. However, our results already indicate that a potent stimulation of NMDA receptors induces several presynaptic regulatory processes on DA release that, for some of them, differ in the two striatal compartments. Presently, most of the TTX-resistant regulatory processes seem to be similar in both compartments while those that are TTX-sensitive differ in several aspects in striosome- and matrix-enriched areas. In the presence of TTX, both GABA and dynorphin, likely originating from dendrites of the medium-sized spiny neurons, reduce the amplitude of the NMDA-evoked release of DA. In the absence of TTX, by activating local circuits depending on nerve impulse flow, NMDA stimulates much more the release of DA in the matrix than in the striosomes. This occurs in spite of inhibitory processes, which are revealed in the presence of naloxone and bicuculline and which are of larger amplitude in the striosomes than in the matrix. In the striosomes, in addition to dynorphin, another opiate peptide that could be released from another population of cells seems also to be involved in this inhibitory regulation. Finally, the additivity of the disinhibitory effects of bicuculline and naloxone in the matrix suggests that the GABAand dynorphin-dependent inhibitory presynaptic controls of DA release occur in distinct matrix areas in the rat as previously shown in the cat (Kemel et al., 1992). This raises interesting questions concerning cotransmission processes. In this context, tachykinins are also contained in medium-sized spiny neurons, and we have shown that substance $P$ facilitates DA release in both striatal compartments through a TTX-sensitive process while neurokinin A and neurokinin B stimulate DA release only in the matrix through processes that are, respectively, partially and totally TTX resistant (Tremblay et al., 1992). The intervention of these peptides in the regulation of DA release has still to be demonstrated under the action of NMDA. Altogether, our results also indicate that NMDA activates the mediumsized spiny neurons of the striosomes and the matrix since TTXsensitive responses were seen in both compartments. The activation of striosome efferent neurons may have important consequences in vivo in the regulation of the activity of the populations of nigrostriatal DA neurons that project either to the striosomes or to both striatal compartments.

\section{References}

Barbicto L, Chéramy A, Godehcu G, Descc JM, Glowinski J (1990) Glutamate receptors of a quisqualate-kainate subtype are involved 
in the presynaptic regulation of dopamine release in the cat caudate nucleus in vivo. Eur $\mathbf{J}$ Neurosci 2:304-311.

Besson MJ, Graybiel AM, Quinn B (1990) Co-expression of neuropeptides in the cat's striatum: an immunohistochemical study of substance $\mathbf{P}$, dynorphin B and enkephalin. Neuroscience 39:33-58.

Bouyer JJ, Park DH, Joh TH, Pickel VM (1984) Chemical and structural analysis of the relation between cortical inputs and tyrosine hydroxylase-containing terminals in rat neostriatum. Brain Res 302: 267-275.

Chéramy A, Romo R, Godeheu G, Baruch P, Glowinski J (1986) In vivo presynaptic control of dopamine release in the cat caudate nucleus. II: facilitatory or inhibitory influence of L-glutamate. Neuroscience 19:1081-1090.

Chesselet MF, Cheramy A, Reisine TD, Lubetzki C, Desban M, Glowinski J (1983) Local and distal effects induced by unilateral striatal application of opiates in the absence or in the presence of naloxone on the release of dopamine in both caudate nuclei and substantia nigrae of the cat. Brain Res 258:229-242.

Clow DW, Jhamandas K (1989) Characterization of L-glutamate action on the release of endogenous dopamine from rat caudate-putamen. J Pharmacol Exp Ther 248:722-728.

Desban M, Kemel ML, Glowinski J, Gauchy C (1993) Spatial organization of patch and matrix compartments in the rat striatum. Neuroscience 57:661-671.

Desce JM, Godeheu G, Galli T, Artaud F, Chéramy A, Glowinski J (1992) L-Glutamate-evoked release of dopamine from synaptosomes of the rat striatum: involvement of AMPA and $N$-methyl-D-aspartate receptors. Neuroscience 47:333-339.

Dumuis A, Sebben M, Haynes L, Pin JP, Bockaert J (1988) NMDA receptors activated the arachidonic acid cascade in striatal neurons. Nature 336:68-70.

Freund TF, Powell J, Smith AD (1984) Tyrosine hydroxylase-immunoreactive boutons in synaptic contact with identified striato-nigral neurons, with particular reference to dendritic spines. Neuroscience 13:1189-1215

Galli T, Godeheu G, Artaud F, Desce JM, Pittaluga A, Barbeito L, Glowinski J, Cheramy A (1991) Specific role of $N$-acetyl-aspartylglutamate in the in vivo regulation of dopamine release from dendrites and nerve terminals of nigrostriatal dopaminergic neurons in the cat. Neuroscience 42:19-28.

Galli T, Desce JM, Artaud F, Kemel ML, Cheramy A, Glowinski J (1992) Modulation of GABA release by AMPA and NMDA receptors in matrix-enriched areas of the rat striatum. Neuroscience 50:769780.

Gauchy C, Desban M, Krebs MO, Glowinski J, Kemel ML (1991) Role of dynorphin-containing neurons in the presynaptic inhibitory control of the acetylcholine-evoked release of dopamine in the striosomes and the matrix of the cat caudate nucleus. Neuroscience 41 : $449-458$.

Gerfen CR (1989) The neostriatal mosaic: striatal patch-matrix organization is related to cortical lamination. Science 246:385-387.

Gerfen CR (1992) The neostriatal mosaï: multiple levels of compartmental organization. Trends Neurosci 15:133-138.

Gerfen CR, Young SW III (1988) Distribution of striatonigral and striatopallidal peptidergic neurons in both patch and matrix compartments: an in situ hybridization histochemistry and fluorescent retrograde tracing study. Brain Res 460:161-167.

Giorguieff MF, Kemel ML, Glowinski J (1977) Presynaptic effect of L-glutamic acid on the release of dopamine in rat striatal slices. Neurosci Lett 6:73-77.

Graybiel AM (1990) Neurotransmitters and neuromodulators in the basal ganglia. Trends Neurosci 13:244-254.

Graybiel AM, Ragsdale CW (1978) Histochemically distinct compartments in the striatum of human, monkey and cat demonstrated by acetylthiocholinesterase staining. Proc Natl Acad Sci USA 75: 5723-5727.

Hamel E, Beaudet A (1984) Electron microscopic autoradiographic localization of opioid receptors in rat neostriatum. Nature 312:155157.

Hamel E, Beaudet A (1987) Opioid receptors in rat neostriatum: radioautographic distribution at the electron microscopic level. Brain Res 401:239-257.

Hansbauer I, Wink D, Osawa Y, Edelman GM, Gally JA (1992) Role of nitric oxide in NMDA-evoked release of ${ }^{3} \mathrm{H}$-dopamine from striatal slices. Neuroreport 3:409-412.
Herkenham M, Pert CB (1981) Mosaic distribution of opiate receptors, parafascicular projections and acetylcholinesterase in rat striatum. Nature 291:415-418.

Johnson KM, Jeng YJ (1991) Pharmacological evidence for $N$-methylD-asparate receptors on nigro-striatal dopaminergic nerve terminals. Can J Physiol Pharmacol 69:1416-1421.

Kemel ML, Desban M, Glowinski J, Gauchy C (1989) Distinct presynaptic control of dopamine release in striosomal and matrix areas of the cat caudate nucleus. Proc Natl Acad Sci USA 86:9006-9010.

Kemel ML, Desban M, Glowinski J, Gauchy C (1992) Functional heterogeneity of the matrix compartment in the cat caudate nucleus as demonstrated by the cholinergic presynaptic regulation of dopamine release. Neuroscience 50:597-610.

Krebs MO, Kemel ML, Gauchy C, Desban M, Glowinski J (1989) Glycine potentiates the NMDA-induced release of dopamine through a strychnine-insensitive site in the rat striatum. Eur J Pharmacol 166: 567-570.

Krebs MO, Desce JM, Kemel ML, Gauchy C, Godeheu G, Cheramy A, Glowinski J (1991a) Glutamatergic control of dopamine release in the rat striatum: evidence for presynaptic NMDA receptors on dopaminergic nerve terminals. J Neurochem 56:81-85.

Krebs MO, Trovero F, Desban M, Gauchy C, Glowinski J, Kemel ML (1991b) Distinct presynaptic regulation of dopamine release through NMDA receptors in striosome- and matrix-enriched areas of the rat striatum. J Neurosci 11:1256-1262.

Krebs MO, Kemel ML, Gauchy C, Desban M, Glowinski J (1993) Local GABAergic regulation of the NMDA-evoked release of dopamine is more important in striosomes than in matrix of the rat striatum. Neuroscience 57:249-260.

Leviel V, Gobert A, Guibert B (1990) The glutamate-mediated release of dopamine in the rat striatum: further characterization of the dual excitatory-inhibitory function. Neuroscience 39:305-312.

Lubetzki C, Chesselet MF, Glowinski J (1982) Modulation of dopamine release in rat striatal slices by delta opiate agonists. J Pharmacol Exp Ther 222:435-440.

Marin P, Quignard JF, Lafon-Cazal M, Bockaert J (1993) Non-classical glutamate receptors, blocked by both NMDA and non-NMDA antagonists, stimulate nitric oxide production in ncurons. Neuropharmacology 32:29-36.

Mulder AH, Wardeh G, Hogenboom F, Frankhuyzen AL (1984) Kand D-opioid receptor agonists differentially inhibited striatal dopamine and acetylcholine release. Nature 308:278-280.

Mulder AH, Wardeh G, Hogenboom F, Frankhuyzen AL (1989) Selectivity of various opioid peptides towards delta-, kappa- and muopioid receptors mediating presynaptic inhibition of neurotransmitter release in the brain. Neuropeptides 14:99-104.

Murphy SN, Thayer SA, Miller RJ (1987) The effect of excitatory amino acids on intracellular calcium in single striatal mouse neurons in vitro. J Neurosci 7:4145-4158.

Nieoullon A, Cheramy A, Glowinski J (1978) Release of dopamine evoked by electrical stimulation of the motor and visual areas of the cerebral cortex in both caudate nuclei and in substantia nigra in the cat. Brain Res 145:69-83.

Nieoullon A, Kerkerian L, Dusticier N (1983) Presynaptic controls in the neostriatum: reciprocal interactions between the nigrostriatal dopaminergic neurons and the corticostriatal glutamatergic pathway. Exp Brain Res [Suppl] 7:54-65.

Paxinos G, Watson C (1986) The rat brain in stereotaxic coordinates. Merrickville, Australia: Academic.

Pentney RJW, Gratton A (1991) Effects of local delta and mu opioid receptor activation on basal and stimulated dopamine release in striatum and nucleus accumbens of rat: an in vivo electrochemical study. Neuroscience 45:95-102.

Petit F, Hamon M, Fournie-Zaluski MC, Roques BP, Glowinski J (1986) Further evidence for a role of $d$-opiate receptors in the presynaptic regulation of newly synthesized dopamine release. Eur J Pharmacol 126:1-9.

Ransom RW, Deschenes NL (1989) Glycine modulation of NMDAevoked release of $\left[{ }^{3} \mathrm{H}\right]$ acetylcholine and $\left[{ }^{3} \mathrm{H}\right]$ dopamine from rat striatal slices. Neurosci Lett 96:323-328.

Roberts PJ, Anderson SD (1979) Stimulatory effect of L-glutamate and related amino acids on ${ }^{3} \mathrm{H}$-dopamine release from rat striatum: an in vitro model for glutamate actions. J Neurochem 32:1539-1545. Roberts PJ, Sharif NA (1978) Effects of L-glutamate and related amino 
acids upon the release of $\left[{ }^{3} \mathrm{H}\right]$-dopamine from rat striatal slices. Brain Res 157:391-395.

Sharif NA, Hughes J (1989) Discrete mapping of brain mu and delta opioid receptors using selective peptides: quantitative autoradiography, species differences and comparison with kappa receptors. Peptides 10:499-522.

Smith AD, Bolam JP (1990) The neural network of the basal ganglia as revealed by the study of synaptic connections of identified neurones. Trends Neurosci 13:259-265.

Snell L.D, Johnson KM (1987) Characterization of the inhibition of excitatory amino acid-induced neurotransmitter release in the rat striatum by phencyclidine-like drugs. J Pharmacol Exp Ther 238: 938-946.

Somogy P, Bolam JP, Smith AD (1981) Monosynaptic cortical input and local axon collaterals of identified striatonigral neurons. A light and electron microscopic study using the Golgi-peroxidase transportdegeneration procedure. J Comp Neurol 195:567-584.

Tempel A, Zukin RS (1987) Neuroanatomical patterns of the m, d and $\mathrm{k}$ opioid receptors of the rat brain as determined by quantitative in vitro autoradiography. Proc Natl Acad Sci USA 84:4308-4312.
Tremblay L, Kemel ML, Desban M, Gauchy C, Glowinski J (1992) Distinct presynaptic control of dopamine release in striosomal- and matrix-enriched areas of the rat striatum by selective agonists of NK1, NK2 and NK3 tachykinin receptors. Proc Natl Acad Sci USA 89: $11214-11218$.

Wang JKT (1991) Presynaptic glutamate receptors modulate dopamine release from striatal synaptosomes. J Neurochem 57:819-822.

Werling LL, Frattali A, Portoghese PS, Takemori AE, Cox BM (1988) Kappa receptor regulation of dopamine release from striatum and cortex of rats and guinea pigs. J Pharmacol Exp Ther 246:282-286.

Williams JC, Berbekar I, Weiss S (1991) $N$-methyl-D-asparate evokes the release of somatostatin from striatal interneurons in primary culture. Neuroscicnce 43:437-444.

Wilson CJ, Groves PM (1980) Fine structure and synaptic connections of the common spiny neuron of the rat neostriatum: a study employing intracellular injection of horseradish peroxidase. J Comp Neurol 194: 599-615.

Zhu XZ, Luo LG (1992) Effects of nitropusside (nitric oxide) on endogenous dopamine release from rat striatal slices. J Neurochem 59: 932-935. 